\title{
Oral Cavity Mucoepidermoid Carcinoma
}

National Cancer Institute

\section{Source}

National Cancer Institute. Oral Cavity Mucoepidermoid Carcinoma. NCI Thesaurus. Code C8177.

A mucoepidermoid carcinoma arising from the minor salivary glands in the oral cavity. It is often asymptomatic and detected during a routine dental examination. 